Revista electrónica de difusión científica - Universidad Sergio Arboleda Bogotá - Colombia

http://www.usergioarboleda.edu.co/civilizar Reservados todos los derechos de autor No. 11

\title{
IMPACTO EN COLOMBIA DE LA LEX MERCATORIA
}

\author{
Walter René Cadena Afanador ${ }^{1}$ \\ Director Grupo Derecho Privado y Globalización, DPG \\ Categoría A - Colciencias, Universidad Libre
}

\section{RESUMEN}

Este ensayo propone analizar del fenómeno de la nueva Lex Mercatoria y evaluar su probable asimilación en el sistema normativo colombiano. Dejando a un lado los debates teóricos sobre la existencia o no de la nueva Lex Mercatoria, así como los debates centrados en su legitimidad o conveniencia, se parte de una lectura transdisciplinaria de las Ciencias Jurídicas, apoyado en otras ciencias como la Economía o las Relaciones Internacionales.

Con este propósito se estudia la antigua Lex Mercatoria como antecedente medieval de la actual Lex. Después se analiza el marco estructural de la Nueva Lex a partir de su conceptualización, fuentes, características, actores y causas que la promueven a nivel internacional. Finalmente se aborda la asimilación en Colombia de la Convención de las Naciones Unidas sobre los Contratos de Compraventa Internacional de Mercaderías, los Principios de Unidroit, las Reglas y Usos Uniformes para Crédito Documentario y algunos íconos jurisprudenciales.

\section{ABSTRACT}

This test proposes to analyze of the phenomenon of the new Lex Mercatoria and to evaluate its probable assimilation in the Colombian normative system. Leaving to a side the theoretical debates on the existence or not of the new Lex Mercatoria, as well as the debates trims in its legitimacy or convenience, part of a transdisciplinaria reading of Legal Sciences, supported in other sciences like the Economy or the International Relations.

With this intention the old Lex Mercatoria like medieval antecedent of the present Lex studies. Later one analyzes the structural frame of the New Lex from his conceptualización, sources, characteristics, actors and causes that promote it at international level. Finally is approaches the assimilation in Colombia of the International Sale of Goods Convention of the Nations United, the Principles of Unidroit, Uniform Customs and Practices for Documentary Credits and some jurisprudences.

\footnotetext{
${ }^{1}$ Abogado, Magíster en Relaciones Internacionales. Autor de tres libros y varios artículos. Actualmente se desempeña como Director del programa de Relaciones Internacionales y Estudios Políticos a Distancia de la Universidad Militar Nueva Granada e Investigador externo del Centro de Investigaciones Sociojurídicas de la Universidad Libre. Par académico del Ministerio de Educación Nacional, Par investigador de Colciencias. Email: walterc@umng.edu.co; walter.cadena@gmail.com.
} 
Revista electrónica de difusión científica - Universidad Sergio Arboleda Bogotá - Colombia

http://www.usergioarboleda.edu.co/civilizar Reservados todos los derechos de autor No. 11

\section{PALABRAS CLAVE}

Lex Mercatoria, Derecho Internacional, Contratación Internacional, Arbitraje, Costumbre Mercantil, Crédito Documentario, Incoterms, Globalización del Derecho.

\section{KEY WORDS}

Lex Mercatoria, Internacional Law, Internacional Contract, Arbitration, Costumbre Mercantil, Credit Documentary, Incoterms, Globalization of Law.

\section{INTRODUCCIÓN}

El panorama que define la epistemología jurídica tradicional, esto es, la forma de comprender, estudiar y enseñar las Ciencias Jurídicas en los últimos siglos, se está transformado y redefiniendo de manera constante.

Las columnas que han sostenido por más de nueve siglos las estructuras tradicionales del Derecho se han caracterizado por concebirlo dentro de la familia romanista como un Derecho formal, positivista, local y primordialmente controlado por los Estados. Se podría decir que su naturaleza ha sido histórica, convencional, positiva y mutable y que su objetivo fundamental es la regulación de las razones humanas.

Pero de unas décadas para acá, estos preceptos se han reconfigurado notablemente al encontrarse la sociedad ante una serie de fenómenos e imperativos que obligan a una interpretación jurídica diferente. Esta serie de fenómenos e imperativos han sido denominados como "creciente interdependencia", mundialización, nuevo orden mundial o simplemente globalización.

En este contexto, una urgencia sentida en el entorno jurídico internacional es la de implementar un medio jurídico para la solución de los conflictos comerciales y mercantiles que se caracterice por su flexibilidad, eficacia y universalidad.

Es reconocido que el actual sistema legal de contratación internacional no satisface todos los requerimientos de los actores internacionales del comercio. Ellos buscan estructurar una alternativa jurídica que sea adecuada a sus operaciones y necesidades, basándose, para ello, en la repetición de cláusulas contractuales y elaboración de contratos - tipo, la consolidación de usos y costumbres mercantiles, la utilización del arbitraje internacional en la solución de sus conflictos comerciales, la creación de regulaciones profesionales, y la realización de diversos esfuerzos de armonización y unificación internacional de las normas comerciales. 
Revista electrónica de difusión científica - Universidad Sergio Arboleda Bogotá - Colombia

http://www.usergioarboleda.edu.co/civilizar Reservados todos los derechos de autor No. 11

Esta serie de tendencias regulativas ha sido denominada como nueva Lex Mercatoria o nuevo lus Mercatorum. Dicho término fue identificado y desarrollado en la época moderna por los juristas Berthold Goldman, Clive Schmitthoff y Pierre Lalive.

\section{LOS ANTECEDENTES: LA ANTIGUA LEX MERCATORIA}

La antigua Lex Mercatoria remonta sus orígenes a comienzos del siglo XII de nuestra Era y su desarrollo se prolongó por más de cuatro siglos. Su surgimiento coincide con el nacimiento de una nueva capa social integrada por artesanos y comerciantes, quienes se organizaron en corporaciones y gremios y que era conocida como la Societas Mercatorum.

La actividad era de naturaleza internacional, y tornaba inapropiadas las exiguas leyes locales en materia mercantil.

Así, la Societas Mercatorum, tratada en un comienzo como una clase de parias medievales, rompió los esquemas sociales y económicos. Adquirió mayor poder en la medida en que se organizaba a la par que encontró en el contrato comercial con un magnífico aliado que permitió la acumulación capitalista y el desarrollo del capitalismo como sistema. ${ }^{2}$

Los mercaderes comerciaban sus productos en las ferias regionales de la Europa Feudal, sin miramientos de fronteras ni leyes feudales. Las ferias medievales se celebraban anualmente y recibían comerciantes de distintos orígenes y lenguas, quienes acudían a ellas durante varias semanas con el aval del Rey anfitrión, quien permitía a los mercaderes arreglar entre ellos sus litigios comerciales, controlando el correcto flujo del dinero transado.

A su vez se desarrollaron las corporaciones las cuales alcanzaron su mayor esplendor en los siglos XIII y XIV debido a que poseían órganos propios de dirección, autonomía normativa y jurisdicción especial para aplicarla. Poco a poco se diferenciaron conceptualmente los gremios (organizaciones asociativas de carácter local) de las corporaciones, llamadas también guildas o hansas (conformadas por grandes comerciantes que reglamentaban y controlaban el tráfico interlocal e internacional).

Los gremios no eran excluidos de la tutela de las corporaciones, tratándolas teóricamente vis-a-vis. Desde esta época las corporaciones alcanzaron una mayor capacidad autonómica y creadora de poder; de esta manera, las corporaciones surgieron como "un hecho nuevo vinculado a la constitución del municipio y a la fuerte inmigración de los campos a la ciudad, imitando la estructura corporativa. La

\footnotetext{
${ }^{2}$ Sombart (1967: 167).
} 
Revista electrónica de difusión científica - Universidad Sergio Arboleda Bogotá - Colombia

http://www.usergioarboleda.edu.co/civilizar Reservados todos los derechos de autor No. 11

historia de las corporaciones terminará a veces por entremezclarse con la constitucional de la ciudad"3.

No obstante su origen consuetudinario, la Lex Mercatoria se plasmó por escrito (v.g.: Consuetudines de Genova, 1056; Constitutum usus de Pisa, 1161; Liber consuetudinum de Milán, 1216), luego se recogió en Estatutos Corporativos (como el del Arte de la Lana de Florencia, 1301; el Breve Mercatorum de Pisa, 1316; Ios Statuti dei mercanti de Parma, Piacenza, Brescia, Roma, Verona, Milán, etc.) y estos a su vez se integraron en tratados interlocales e internacionales (v.g.: Capitulare nauticum de Venecia; las Tavole amalfitane; los ordenamientos de Trani; el Breve Curiae maris de Pisa, entre otros).

Al Derecho Mercantil medieval se le conoció con diversos nombres: lus Mercatorum, Derecho Corporativo, Lex Mercatoria. o Law Merchant. Se considera que se trató de un Derecho especial de producción autónoma, siendo sus fuentes principales la costumbre mercantil, las disposiciones del poder público (provenientes de las ciudades y los feudos) y los esfuerzos de armonización interlocal surgidos de los intercambios comerciales.

La Lex Mercatoria se caracterizó por ser cosmopolita, transnacional, consuetudinaria y clasista (dirigida, de manera exclusiva, hacia la societatem mercatorum). Su cosmopolitismo se basó en la flexibilidad, especialidad (entendida como Derecho de clase) y autonomía.

La importancia de la Lex Mercatoria decayó a mediados del siglo XVI. Contribuyó a este descenso, la consolidación del Derecho Estatal en cabeza del Estado moderno, la cual absorbió y prohibió la Lex Mercatoria transnacional; el desplazamiento geográfico de los principales centros comerciales desde Italia y el norte de Alemania hacia Holanda Inglaterra y Francia, y las falencias internas de la Lex Mercatoria que la habían tornado menos transparente, impredecible y parcializada en su aplicación.

Desde entonces, la Lex Mercatoria no volvió a alcanzar el auge y reconocimiento logrado durante la Edad Media; fue borrada del mapa de la historia jurídica hasta hace poco, cuando han sido comparadas sus características con nuestra época y se habla de su probable resurgimiento.

\section{LA NUEVA LEX MERCATORIA}

\footnotetext{
${ }^{3}$ Ascarelli (1947: 32).
} 
Revista electrónica de difusión científica - Universidad Sergio Arboleda Bogotá - Colombia

http://www.usergioarboleda.edu.co/civilizar Reservados todos los derechos de autor No. 11

La nueva Lex Mercatoria o nuevo lus Mercatorum fue un concepto identificado y desarrollado de manera pionera por Berthold Goldman, Clive Schmitthoff y Pierre Lalive a partir de la década de 1950.

Para el tratadista Olé Landó el 21 de junio de 1985 marcó el hito histórico en que un instrumento jurídico internacional reconoció la procedencia de la nueva Lex Mercatoria como fuente para la resolución de un conflicto en materia comercial. Se trata del artículo 28 (1) de la Ley - tipo de la CNUDMI sobre Arbitraje Internacional Comercial, la cual establece que las normas aplicable al fondo del litigio que el tribunal arbitral decidirá el litigio de conformidad con las normas de derecho elegidas por las partes como aplicables al fondo del litigio.

Podemos definir la nueva Lex Mercatoria como un conjunto de principios, reglas, usos e instituciones de derecho mercantil y comercial principalmente, que posee una vocación para ser utilizado como un derecho de clase, informal e internacional y regulado jurisdiccionalmente por el arbitraje internacional.

Su naturaleza jurídica se concibe como un conjunto histórico y actual de usos y prácticas comerciales consuetudinarias que mediante la aceptación coetánea de ciertas reglas de conducta por parte de los actores económicos internacionales, permite además de realizar diversas transacciones comerciales, resolver jurisdiccionalmente las controversias a través del arbitraje.

La nueva Lex Mercatoria se configura como un fenómeno de transnacionalización del Derecho Comercial Internacional, el cual excede la esfera estatal y se configura como un derecho de clase, autónomo e informal en cabeza de las empresas transnacionales y multinacionales.

\section{FUENTES DE LA NUEVA LEX MERCATORIA}

Las fuentes de donde emerge la Lex Mercatoria son principalmente:

- Los usos y costumbres. En algunos casos estos usos y costumbres pueden ser tomados como fuente principal de obligaciones, en virtud del principio de autonomía de la voluntad, tal como lo establece la Convención de Viena de 1890 sobre contratos de compraventa internacional, en la cual en su artículo 9 expresa "las partes quedarán obligadas por cualquier uso en que hayan convenido y por cualquier práctica que hayan establecido entre ellas. Salvo pacto en contrario, se considerará que las partes han hecho tácitamente aplicable al contrato o a su formación un uso del que tenían o debían haber tenido conocimiento y que, en el comercio internacional, sea ampliamente conocido y regularmente observado por las partes en contratos del mismo tipo en el tráfico mercantil de que se trate". 
Revista electrónica de difusión científica - Universidad Sergio Arboleda Bogotá - Colombia

http://www.usergioarboleda.edu.co/civilizar Reservados todos los derechos de autor No. 11

Dentro de los usos mercantiles más conocidos y observados por los comerciantes se pueden citar los Incoterms, las Reglas uniformes relativas a los cobros, las Reglas y Usos uniformes para Crédito Documentario y las Reglas uniformes para las garantías contractuales emanadas de la Cámara de Comercio Internacional de París.

- Los contratos tipo. Debido a la variedad legislativa en materia de contratación internacional y más específicamente en lo que tiene que ver con la circulación de mercancías (bienes y servicios) a nivel internacional, organismos y asociaciones profesionales han elaborado una serie de contratos tipo buscando la estandarización de los modelos de contrato.

Dentro de las organizaciones que han sido pioneras en la elaboración de modelos de condiciones generales de sus respectivas profesiones, se destacan la Federación Internacional de Ingenieros Consultores (FIDIC), The Association of West European Ship, The Grain and Feed Trade Association (GAFTA), American Cotton Shippers Association y Asociación de Propietarios Aserraderos Finlandeses.

Con esta estandarización se pretende de un lado proteger la autonomía contractual de las partes en el escenario internacional y de otro establecer una serie de condiciones generales de venta, para de esta forma imprimirles una mayor seguridad normativa a estos documentos.

El empleo en forma reiterada de estos modelos, le han dado el carácter de norma consuetudinaria de gran valor para las partes implicadas en la contratación internacional.

- Los códigos de conducta. Tienen el carácter de recomendaciones -no vinculantes- y se constituyen en una forma de materialización del derecho consuetudinario. Su función primordial consiste en llenar los vacíos normativos en materia de empresas corporativas.

Unos de los códigos de conducta más reconocidos internacionalmente es el de las Naciones Unidas, en el cual se procura regular los parámetros de conducta de las empresas corporativas y su sujeción al derecho nacional del país anfitrión.

- El arbitraje internacional. Tal como señala Guardiola, el arbitraje es la principal institución que permite a las partes involucradas en una controversia, eludir la vía judicial, sometiendo la resolución de aquélla a un tercero, árbitro, o a un organismo determinado que se encargue del nombramiento del mismo ${ }^{4}$.

\footnotetext{
${ }^{4}$ Guardiola (1994: 25).
} 
Revista electrónica de difusión científica - Universidad Sergio Arboleda Bogotá - Colombia

http://www.usergioarboleda.edu.co/civilizar Reservados todos los derechos de autor No. 11

En desarrollo de las relaciones comerciales a nivel internacional es frecuente que surjan conflictos y para dar solución a estos se han creado organismos especializados que a través del arbitraje han desarrollado procedimientos ágiles y eficaces para resolver dichas controversias, así el arbitraje internacional y la jurisprudencia de él emanada se han constituido en otra de los pilares a la hora de hablar de Lex Mercatoria.

Ante la creciente inoperatividad de las legislaciones nacionales en materia de comercio internacional, el arbitraje surge como una solución bastante aceptada, en la cual prima la voluntad de las partes -escogencia del derecho aplicable, designación de árbitros, etc.-, para de esta forma sustraerse a las jurisdicciones nacionales y centrarse más en la aplicación de los usos y costumbres internacionalmente aceptados.

El árbitro internacional, a diferencia del nacional, tiene mayor inclinación en admitir el uso de la Lex Mercatoria, ya que acude a la fuente directa del conflicto, es decir al contenido sustancial del contrato, examinando su sustancia, sus objetivos, las circunstancias particulares de ejecución y la voluntad de las partes respecto al derecho a aplicar en caso de conflicto.

- Los tratados internacionales. Han sido reconocidos por algunos doctrinantes como fuente supletoria de la Lex Mercatoria, en buena medida, al escaso desarrollo normogénico del derecho consuetudinario internacional en materia de principios económicos especiales.

En este orden, los acuerdos y tratados de comercio internacional cobran un decisivo significado como fuente de la nueva Lex Mercatoria, tal como se evidencia en materia de contratación internacional y el derecho de integración, por citar solo dos ejemplos.

\section{CARACTERÍSTICAS DE LA NUEVA LEX MERCATORIA}

La transición económica hacia una economía de mercado globalizada y el consecuente surgimiento de nuevos actores económicos en el contexto internacional, ponen en evidencia la crisis del derecho nacional como normatividad estática, por lo cual se hace necesario la adopción de nuevas normas que respondan a la movilidad del mercado y que faciliten el desarrollo de las relaciones comerciales entre los actores económicos.

Esta Lex Mercatoria ha sido caracterizada como: ${ }^{5}$

- Un derecho anacional y desterritorializado, no enmarcado dentro de las fronteras de los estados nacionales.

\footnotetext{
${ }^{5}$ Esta propuesta de caracterización retoma los trabajos formulados por Boaventura de Sousa, Fernando Mantilla, Paul Lagarde, Jean Denis Bredin y Carlos Espinosa, entre otros.
} 
Revista electrónica de difusión científica - Universidad Sergio Arboleda Bogotá - Colombia

http://www.usergioarboleda.edu.co/civilizar Reservados todos los derechos de autor No. 11

- Responde a las necesidades de los comerciantes, es creación de ellos y defiende sus intereses de clase.

- Coercibilidad, en el sentido de la aceptación que tienen los actores económicos internacionales frente a las reglas de conducta que ellos mismos establecen para el desarrollo de su actividad.

- Garantiza la prelación del principio de la autonomía de las partes en un contrato internacional.

- Se desarrolla en un contexto en el cual el estado-nación pierde su papel principal en las relaciones económicas, pasa a un segundo plano (es el brazo secular para asegurar la ejecución de los laudos arbitrales), tiene poca injerencia en las relaciones comerciales a escala internacional.

- Rompe los esquemas del derecho estático flexibilizando las relaciones comerciales internacionales.

- Establece un sistema de jerarquías entre los actores del orden económico mundial.

- Replanteamiento del estado-nación, desterritorialización y reterritorialización para favorecer los derechos de los inversionistas.

- Se convierte en la mejor forma de internacionalización del capital, ya que brinda a los inversores internacionales mayores facilidades a la hora de permear los mercados locales.

- Busca garantizar transacciones seguras y predecibles.

- Desarrolla procedimientos ágiles y efectivos, lo cual le da una ventaja sobre la complejidad e ineficacia que en muchas ocasiones representan los procedimientos de los derechos locales.

- Su principal herramienta de tipo jurisdiccional es el arbitraje internacional, el cual garantiza a las partes una mayor neutralidad y conocimiento por parte de quien administra justicia.

Así la nueva Lex Mercatoria surge como respuesta a estas inquietudes, tratando de establecer unas reglas de juego que se adapten a la dinámica del mercado que debido a su volatilidad requiere de una flexibilización del derecho, de las prácticas comerciales y del papel de los estados nacionales en las esferas del comercio internacional.

\section{ACTORES $Y$ CAUSAS QUE PROMUEVEN LA NUEVA LEX MERCATORIA}

Los factores que dieron origen a la nueva Lex Mercatoria son diversos y están íntimamente relacionados con los retos generados a partir del fenómeno de la globalización que impactan el campo de la ciencias jurídicas.

La nueva Lex Mercatoria surge de una especie de conciencia común de los actores económicos internacionales por crear alternativas jurídicas que no estén 
Revista electrónica de difusión científica - Universidad Sergio Arboleda Bogotá - Colombia

http://www.usergioarboleda.edu.co/civilizar Reservados todos los derechos de autor No. 11

limitadas al Derecho Estatal, el cual se ha vuelto lento y poco práctico frente a la rápida dinámica del comercio internacional.

Es muy probable que la nueva Lex Mercatoria no conduzca al resurgimiento exacto de la Lex Mercatoria medieval, a manera de un preciso calco. Ésta es la opinión de Feldstein, quien afirma que "la nueva Lex Mercatoria no es una vuelta a la antigua, sino que es otra Lex Mercatoria, con diverso contenido, alcance y características que la originaría"6.

Después de cuatrocientos años de desaparición de la Lex Mercatoria medieval el contexto histórico, económico y jurídico es diferente en muchos aspectos; pero no por ello se pueden desconocer ciertos rasgos comunes entre estas dos épocas, como:

- $\quad$ La creciente disfuncionalidad del ente político dominante -feudal o estatalrespecto al comercio internacional;

- $\quad$ La consolidación de nuevos actores económicos en el escenario mundial;

- $\quad$ El interés de estos nuevos actores económicos en crear un sistema normativo flexible y alternativo al Derecho local, llámese Derecho Feudal o Derecho Nacional según la época.

- Una consciencia internacional de clase por parte de la societas mercatorum, que a su vez procura formular un cuerpo normativo o Derecho de clase.

Los principales actores que impulsan la implementación y desarrollo de la nueva Lex Mercatoria son:

- $\quad$ Los operadores del comercio internacional (V. g.: empresas corporativas, sociedades internacionales con ánimo de lucro).

- Las corporaciones jurídicas internacionales.

- $\quad$ Las organizaciones internacionales gubernamentales (V. g.: La Comisión de las Naciones Unidas para el Derecho Mercantil Internacional -CNUDMI-, La Organización Mundial de la Propiedad Intelectual -OMPI-, CIADI y Organización Mundial del Comercio, Banco Mundial).

- Las organizaciones internacionales no gubernamentales (V. g.: Instituto Internacional para la Unificación del Derecho Privado y la Cámara de Comercio Internacional - $\mathrm{CCl}-$ ).

- Los Procesos de Integración Mundial (V. g.: Unión Europea, ALCA, ASEAN, APEC, NAFTA).

- $\quad$ El arbitramento, mediación y conciliación internacional (V. g.: El Centro de Arbitraje y Mediación de la OMPI, Asociación Americana de Arbitraje -AAA-, La Corte Internacional de Arbitraje de la CCl; El Organismo de Solución de Diferencias de la OMC, La Comisión Interamericana de Arbitraje Comercial -CIAC-, Centro Internacional de Diferencias Relativas a Inversiones -CIADI-.

\footnotetext{
${ }^{6}$ Feldstein (1995: 164).
} 
Revista electrónica de difusión científica - Universidad Sergio Arboleda Bogotá - Colombia

http://www.usergioarboleda.edu.co/civilizar Reservados todos los derechos de autor No. 11

- La mayoría de Estados desarrollados ubicados entre las principales economías del mundo (V. g.: Los Estados Unidos de América, Países miembros de la Unión Europea, Japón, Australia).

- La academia.

Así mismo se pueden señalar como los principales factores que han sido primordiales para el surgimiento del proceso normogénico de la nueva Lex Mercatoria los siguientes:

- $\quad$ Tendencia repetitiva de las cláusulas en contratos internacionales;

- Homogeneización y reconocimiento de los usos y costumbres comerciales;

- $\quad$ Actividad del arbitraje, mediación y conciliación internacional cada vez más independiente y vinculante;

- $\quad$ Motivación, importancia material y publicidad de la jurisprudencia arbitral;

- Inadaptabilidad de los Derechos Estatales al comercio internacional;

- Estructuración de una comunidad heterogénea de actores económicos internacionales que buscan satisfacer y legitimar sus intereses comunes,

- Reconceptualización de la naturaleza jurídica y características de tèrminos clásicos en la Ciencia Jurídica tales como Ordenamiento Jurídico, Normogénesis, Soberanía, Jerarquización de las normas, Extraterritorialidad de la norma, Supra y Transnacionalidad, por citar solo algunos.

- $\quad$ Evidente y positivo interés de ciertas naciones más desarrolladas por el surgimiento de una alternativa jurídica internacional al Derecho nacional.

\section{LA ASIMILACIÓN DE LA NUEVA LEX MERCATORIA EN COLOMBIA}

A continuación se estudian algunos íconos normativos que denotan una incipiente pero paulatina aceptación y asimilación de la nueva Lex Mercatoria en el sistema jurídico colombiano.

\subsection{CONVENCIÓN SOBRE LOS CONTRATOS DE COMPRAVENTA INTERNACIONAL DE MERCADERÍAS (VIENA: 1980)}

La Convención de las Naciones Unidas sobre los Contratos de Compraventa Internacional de Mercaderías comprende en total 101 artículos y su objetivo es brindar un cuerpo uniforme de reglas que armonizan los principios del comercio internacional.

La Convención proporciona reglas directamente aplicables, esto es, que no se limita a llenar vacíos jurídicos en el ordenamiento nacional, ya que los imperativos de la globalización económica no pueden permitir el lujo de esperar que los Estados se pongan de acuerdo para establecer un régimen legal conveniente para las transacciones comerciales internacionales. 
Revista electrónica de difusión científica - Universidad Sergio Arboleda Bogotá - Colombia

http://www.usergioarboleda.edu.co/civilizar Reservados todos los derechos de autor No. 11

Si bien, la Convención de Viena fue suscrita por Estados, su normatividad incluye a las empresas transnacionales y multinacionales, reconociendo, de manera explícita, la importancia de los usos y prácticas comerciales que han desarrollado. El contenido y esencia de la Convención ha sido un modelo ha seguir por las subsiguientes iniciativas que han pretendido la armonización del Derecho Internacional.

La Convención prevé que el derecho nacional aplicable resuelva ciertos aspectos de la compraventa internacional que ella no regula, tales como:

- La validez del contrato;

- La responsabilidad extracontractual derivada de las mercancías;

- La adquisición de la propiedad de las mercancías;

- El tipo de interés que se pague por cantidades debidas, y

- Las lagunas de la Convención, es decir, los casos que no pueden ser resueltos ni por interpretación de sus artículos ni por la integración de una nueva norma a partir de sus principios.

El espíritu de la Convención de Viena no es el de competir con la nueva Lex Mercatoria por el "estatus de ser la fuente exclusiva legal para el comercio internacional. Aunque las reglas de la Convención son aceptadas por los Estados ellos operan junto con los usos de comercio internacional y el principio de autonomía contractual" ${ }^{7}$.

En esta medida, el artículo $6^{\circ}$. de la Convención le permite a las partes fijar provisiones por fuera de ella. Esto no refleja una falta de confianza por parte de la Convención en sus propias reglas, sino, por el contrario, consagra la defensa del principio de la autonomía de las partes en escoger la ley aplicable. Un cuerpo normativo por más completo que pretenda ser, no puede aglutinar de manera terminante las provisiones requeridas a cada tipo de actividad comercial, y más aún si estamos hablando de un cuerpo de armonización normativa internacional. Por más que se normativicen los tipos y relaciones jurídicas, quedarán vacíos legales que entrarán a ser llenados por la nueva lex mercatoria.

El artículo $7^{\circ}$. señala los criterios de interpretación de la Convención, los cuales deben partir de su naturaleza internacional, la necesidad de promover la uniformidad y la observancia de la buena fe en los tratados internacionales. Por lo tanto, los temas que no sean gobernados por los artículos o los principios generales de la Convención, se regirán por la ley aplicable conforme a las reglas del Derecho Internacional Privado.

El artículo 9 es significativo en relievar la complementación que existe entre la Convención y la nueva lex mercatoria al establecer la preeminencia de los usos

\footnotetext{
${ }^{7}$ Audit (1990: 179).
} 
Revista electrónica de difusión científica - Universidad Sergio Arboleda Bogotá - Colombia

http://www.usergioarboleda.edu.co/civilizar Reservados todos los derechos de autor No. 11

comerciales sin importar si las partes designaron una ley aplicable de manera específica. De por sí, la Convención es la manifestación de las costumbres mercantiles internacionales y por ende, de la nueva lex mercatoria. De esta manera, la costumbre comercial internacional se coloca en el mismo nivel de importancia con el principio de autonomía contractual

La Convención establece que la fuente principal en materia de la compraventa internacional son los usos mercantiles y la autonomía contractual. Así, la lex mercatoria no solo es complementaria de la Convención sino es su fuente principal.

Por medio de la Ley 518 de agosto 4 de 1999, Colombia se ratificó la Convención. Dicha Ley fue declarada exequible por la Corte Constitucional mediante Sentencia C-529-00 del 10 de mayo de 2000, Magistrado Ponente Dr. Antonio Barrera Carbonell.

Los legisladores colombianos establecieron que para la interpretación de la Convención se debe tener en cuenta el carácter internacional y la necesidad de promover la uniformidad en su aplicación y asegurar la observancia de la buena fe en el comercio internacional.

Así mismo, se señaló que toda controversia que se genere a partir de la celebración de un contrato de compraventa, se resolverá bajo los principios generales de la convención, o a falta de tales principios, de conformidad con la ley aplicable en virtud de las normas de derecho internacional privado.

De igual manera se reconoce que las partes involucradas en el contrato de compraventa pueden estipular que en caso de conflicto, se puede buscar su pronta solución acudiendo a los tribunales de arbitramento internacional.

\subsection{PRINCIPIOS UNIDROIT DE LOS CONTRATOS COMERCIALES INTERNACIONALES (ROMA: 1994)}

Elaborados por el Instituto Internacional para la Unificación del Derecho Privado (UNIDROIT por sus siglas en francés), los principios de Unidroit de los contratos comerciales son aplicables a todo tipo de contratos comerciales internacionales.

La Ley 32 de diciembre 30 de 1992 aprobó el estatuto orgánico del Instituto para la Unificación del Derecho Privado, realizado en Roma el 15 de marzo de 1940. Fue adoptado por Colombia con la finalidad de buscar la unificación del derecho privado obteniendo vínculos de armonización y coordinación entre los distintos Estados que aprobaron dicha disposición. 
Revista electrónica de difusión científica - Universidad Sergio Arboleda Bogotá - Colombia

http://www.usergioarboleda.edu.co/civilizar Reservados todos los derechos de autor No. 11

La Ley 32 de 1992 fue declarada exequible por la Corte Constitucional, mediante Sentencia C-048 del 10 de febrero de 1994, magistrado ponente: Dr. Fabio Morón Díaz.

Su aplicabilidad en Colombia al parecer no ha sido amplia, aunque no existen estudios empíricos que lo demuestren. A nivel internacional el Instituto ha realizado un balance positivo a propósito de cumplirse en el 2004 sus primeros 10 años de existencia.

Por ejemplo Michael Bonell sostiene que el balance ha "excedido las más optimistas expectativas" ": UNILEX: la base de datos sobre casos legales y bibliografía internacional relativos a la Convención de Viena y los Principios de Unidroit para septiembre de 2005 contenía 97 decisiones, de las cuales 75 son de sentencias arbitrales y 22 son decisiones de Cortes.

Llama la atención que de la región latinoamericana proviene una decisión de Corte (Corte Suprema de Justicia de Venezuela, 9 de octubre de 1997, Empresas embotelladoras vs Pepsi-Cola Panamericana) y tres de sentencias arbitrales: (Tribunal de Arbitraje Ad - hoc de Buenos Aires, 10 de diciembre de 1997; Corte Internacional de Arbitraje de la CCl - Barranquilla, diciembre de 2000, y Tribunal Arbitral de la Ciudad de Panamá, 24 de febrero de 2001)

A manera de resumen en el siguiente cuadro se comparan los criterios de formación del contrato tomando como referencia los Principios de Unidroit, la Convención de Viena y el Código de Comercio nacional:

\begin{tabular}{|c|c|c|}
\hline Criterio & $\begin{array}{l}\text { Principios de UNIDROIT y } \\
\text { Convención de Viena (1980) }\end{array}$ & Código de Comercio \\
\hline La Oferta & $\begin{array}{l}\text { Toda propuesta de celebrar un } \\
\text { contrato constituye una oferta, si } \\
\text { es suficientemente precisa e } \\
\text { indica la intención del oferente de } \\
\text { quedar vinculado en caso de } \\
\text { aceptación. }\end{array}$ & $\begin{array}{l}\text { La propuesta es el proyecto de } \\
\text { negocio jurídico que una persona } \\
\text { formule a otra, deberá contener } \\
\text { los elementos esenciales del } \\
\text { negocio y ser comunicada al } \\
\text { destinatario. }\end{array}$ \\
\hline $\begin{array}{l}\text { Efectos que } \\
\text { surte la } \\
\text { oferta y la } \\
\text { aceptación }\end{array}$ & $\begin{array}{l}\text { La oferta surte efectos desde el } \\
\text { momento en que llega al } \\
\text { destinatario. } \\
\text { La aceptación surte efectos } \\
\text { cuando la manifestación de llega } \\
\text { al oferente. La aceptación puede }\end{array}$ & $\begin{array}{l}\text { La oferta surte efectos desde la } \\
\text { comunicación por medios } \\
\text { idóneos hasta llegar al } \\
\text { destinatario. }\end{array}$ \\
\hline
\end{tabular}

\footnotetext{
${ }^{8}$ Michael Joachim Bonell, UNIDROIT Principles 2004 - The New Edition of the Principles of International Commercial Contracts adopted by the International Institute for the Unification of Private Law,2004, http://www.unidroit.org/english/principles/contracts/principles2004/2004-1-bonell.pdf consulta del 01 de septiembre de 2005.
} 
Revista electrónica de difusión científica - Universidad Sergio Arboleda Bogotá - Colombia

http://www.usergioarboleda.edu.co/civilizar Reservados todos los derechos de autor No. 11

\begin{tabular}{|c|c|c|}
\hline & $\begin{array}{l}\text { ser retirada si su retiro llega al } \\
\text { oferente antes que la aceptación o } \\
\text { simultáneamente a ella. }\end{array}$ & \\
\hline $\begin{array}{l}\text { Retiro } \\
\text { revocación } \\
\text { de la oferta }\end{array}$ & $\begin{array}{l}\text { Aun siendo irrevocable, la oferta } \\
\text { puede ser retirada, si el } \\
\text { comunicado en tal sentido llega } \\
\text { antes que la oferta. } \\
\text { La oferta puede revocarse en } \\
\text { cualquier momento siempre y } \\
\text { cuando no sea irrevocable oxista } \\
\text { un comunicado o acto que indique } \\
\text { aceptación. }\end{array}$ & $\begin{array}{l}\text { La propuesta será irrevocable. } \\
\text { Por consiguiente, una vez } \\
\text { comunicada, no podrá } \\
\text { retractarse, so pena de } \\
\text { indemnizar los perjuicios que con } \\
\text { su revocatoria cause al } \\
\text { destinatario. } \\
\text { Es posible la revocatoria si el } \\
\text { comunicado llega antes que la } \\
\text { oferta. }\end{array}$ \\
\hline $\begin{array}{l}\text { Modo de } \\
\text { aceptación }\end{array}$ & $\begin{array}{l}\text { Constituye aceptación cualquier } \\
\text { acto o declaración que manifieste } \\
\text { asentimiento a una oferta, } \\
\text { considerando las prácticas entre } \\
\text { las partes. } \\
\text { El silencio por si solo no significa } \\
\text { aceptación. }\end{array}$ & $\begin{array}{l}\text { La aceptación tácita, manifiesta } \\
\text { por un hecho inequívoco de } \\
\text { ejecución del contrato propuesto, } \\
\text { producirá los mismos efectos que } \\
\text { la expresa siempre que el } \\
\text { proponente tenga conocimiento } \\
\text { de tal hecho. }\end{array}$ \\
\hline Rechazo & $\begin{array}{l}\text { La oferta se extingue cuando la } \\
\text { comunicación de su rechazo llega } \\
\text { al oferente. }\end{array}$ & $\begin{array}{l}\text { Cuando la propuesta se haga por } \\
\text { escrito su rechazo se producirá } \\
\text { dentro de los seis días siguientes } \\
\text { a la fecha que tenga la } \\
\text { propuesta. }\end{array}$ \\
\hline $\begin{array}{l}\text { Aceptación } \\
\text { modificativa } \\
\text { de la oferta }\end{array}$ & $\begin{array}{l}\text { Adiciones o modificaciones a la } \\
\text { oferta constituyen contraoferta. } \\
\text { Si las modificaciones no son } \\
\text { sustanciales constituyen parte del } \\
\text { contrato a menos que medie } \\
\text { objeción del oferente. }\end{array}$ & $\begin{array}{l}\text { La oferta condicional o } \\
\text { extemporánea será considerada } \\
\text { como nueva propuesta. }\end{array}$ \\
\hline
\end{tabular}

\subsection{ACEPTACIÓN DE LAS REGLAS Y USOS UNIFORMES PARA CRÉDITO DOCUMENTARIO (RR.UU 500) COMO COSTUMBRE COMERCIAL}

La Cámara de Comercio Internacional de París ha recogido todas aquellas prácticas utilizadas internacionalmente sobre las operaciones de créditos documentarios y las ha plasmado en las Reglas y Usos uniformes para Crédito Documentario, RRUU, conocidas como UCP por sus siglas en inglés, Uniform Customs and Practice for Documentary Credits,

La primera versión fue adoptada por pocos países y presentó algunos problemas que llevaron rápidamente a una primera versión de la $\mathrm{CCl}$ realizado en Viena 
Revista electrónica de difusión científica - Universidad Sergio Arboleda Bogotá - Colombia

http://www.usergioarboleda.edu.co/civilizar Reservados todos los derechos de autor No. 11

(1933). Posteriormente el XIII Congreso de la CCI reunido en Lisboa (1951) realizó una nueva revisión, donde ya expresamente se consagró (artículo 1), que el crédito documentario es una operación independiente del contrato de compraventa el cual sirve como instrumento de liquidación y se exigió además la fijación de un plazo de validez o utilización de la carta de crédito (art. 38 a 41 inclusive); esta nueva versión se conoce como el folleto 151.

El 20 de noviembre de 1962, la CCl aprobó durante su Congreso realizado en París una nueva revisión conocida como el folleto 222, que entró en vigor a partir del $1^{\circ}$ de julio de 1963 por decisión del XIX Congreso de la CCI reunido en Ciudad de México, en abril de 1963. Esta nueva versión de las Reglas y Usos, significó un cambio radicas en la orientación de las mismas, garantizando su subsistencia y haciendo posible que los bancos de muchos países, entre ellos los ingleses, las acogieran a partir de este momento.

Más adelante vino la revisión de 1974 conocida como el folleto 290, que entró a regir a partir del $1^{\circ}$ de octubre de 1975 y debió realizarse para considerar el efecto sobre los documentos de las innovaciones en materia de transporte, por ejemplo la dada en transporte multi-modal.

Una siguiente versión de las Reglas y Usos Uniformes fue aprobada por el Consejo de la $\mathrm{CCl}$ el 21 de junio de 1983, entrando a regir el $1^{\circ}$ de octubre de 1984 y siendo denominada como el folleto 400.

La última revisión fue llevada a cabo en el año de 1993, denominada Folleto o RR.UU 500.

De conformidad con el art. $2^{\circ}$ de la RR.UU, créditos son todo acuerdo, cualquiera que sea su denominación o descripción, por el que un banco, obrando a petición y de conformidad con las instrucciones de un cliente, se obliga a hacer un pago a un tercero, o a aceptar y pagar efectos librados por el beneficiario, o autoriza a otro banco para que efectúe el pago, o para que acepte y pague tales efectos, o autoriza a otro banco para que negocie, contra entrega de los documentos exigidos.

La función primordial del crédito documentario es aportar seguridad en la realización de las transacciones internacionales. En efecto en este tipo de compraventas, la entrega de mercancías por el vendedor y el pago del precio por el comprador no puede realizarse en un mismo momento y en un mismo lugar; en consecuencia de esto se plantea el problema de la seguridad en la contraprestación. El vendedor no está dispuesto a desprenderse de la mercancía sin recibir la contraprestación y, al contrario, el comprador no está dispuesto a efectuar el pago de la mercancía sin recibir la contraprestación. 
Revista electrónica de difusión científica - Universidad Sergio Arboleda Bogotá - Colombia

http://www.usergioarboleda.edu.co/civilizar Reservados todos los derechos de autor No. 11

El crédito documentario permite que el pago del precio se produzca en el instante en el que el vendedor se desapodera de la mercancía, entregando al banco los documentos, entre los cuales y a este fin tiene importancia el Conocimiento de Embarque o la Carta de Porte, en cuanto implican una transmisión al banco de la posesión sobre las mercancías y la legitimación a exigirlas del transportador en el punto de destino.

La UCP 500 son condiciones generales de la contratación, y como tales, no constituyen derecho objetivo, porque su razón de obligar no reside en el poder legislativo nacional o supranacional, ni son propiamente usos de comercio, sino que su eficacia vinculante se encuentra en el consentimiento, expreso o tácito, de los sujetos a quienes pretenden obligar. Sin embargo tienen una clara vocación normativa de regular en abstracto determinadas relaciones de la vida social en defecto de normas legales o en sustitución de las mismas.

Por esta razón, su interpretación no puede quedar enteramente sometida a las normas de interpretación de los contratos, porque los autores del contrato no son en realidad los autores de su contenido (por ejemplo, debe tomarse como elemento de interpretación la evolución histórica de las RRUU a través de las diversas revisiones), poseyendo las características de uniformidad, generalidad y universalidad, como si se tratara de leyes.

El 10 de septiembre de 2002 la Cámara de Comercio de Bogotá certificó las RR.UU 500 como la primera costumbre comercial internacional avalada en Colombia en los siguientes términos: que en Bogotá, D.C. existe la costumbre mercantil de sujetar los derechos y obligaciones que emanan de la apertura $y$ utilización de cartas de crédito en los contratos de compraventa internacional de mercaderías a las reglas y usos uniformes adoptados por la Cámara de Comercio Internacional, en el Folleto 500.

Dicha certificación permite invocar a las RR.UU 500 como fuente de derecho siempre que no haya una estipulación contractual sobre esta materia. De esta manera se respeta la autonomía contractual.

\subsection{ALGUNOS ÍCONOS JURISPRUDENCIALES}

\section{SENTENCIA A-012/99 DE LA CORTE SUPREMA DE JUSTICIA}

Magistrado ponente: Pedro Lafont Pianetta.

Bogotá, D.C., 26 de enero de 1999.

Referencia: Expediente No. 7474.

Merck \& Co. Inc., Merck Frosst Canada Inc. y Frosst Laboratories Inc. VS Tecnoquímicas S.A. 
Revista electrónica de difusión científica - Universidad Sergio Arboleda Bogotá - Colombia

http://www.usergioarboleda.edu.co/civilizar Reservados todos los derechos de autor No. 11

Se determina cuando procede el exequátur en Colombia, partiendo de la noción que múltiples tratados internacionales contienen sobre laudo o sentencia arbitral. Frente al caso sub examine la Corte precisa que:

Los laudos extranjeros que simplemente se limitan a definir la competencia si bien resuelven una diferencia sobre la misma como base para avocar el conocimiento de un asunto, también es cierto que no lo resuelven. Se trata de una resolución de carácter procesal, previa y parcial, que, al no alcanzar la definición en todo o en parte de las diferencias sustanciales, no resulta ser objeto de exequátur en Colombia, tanto mas cuanto su finalidad no sería otra distinta que la de, so pretexto de ejecución de un laudo extranjero, se pretenda en el fondo definir con el exequátur un supuesto conflicto de jurisdicción o competencia entre el arbitramento extranjero y la jurisdicción colombiana, que, por lo demás, desbordaría el marco legal del ordenamiento jurídico colombiano.

En efecto, si las partes que supuestamente han convenido resolver su diferencia mediante arbitramento en el extranjero, difieren en su procedencia, en cuanto unos insisten en que debe ser el Tribunal de Arbitramento extranjero el competente, y otros en que debe serlo la jurisdicción colombiana, promoviendo ambos procesos en el exterior y en Colombia, lo pertinente es que dichos aspectos de competencia sean alegados por los demandados separadamente en cada uno de ellos con los riesgos pertinentes.

Porque, en tal evento, a la parte demandada en el extranjero e interesada en su adelantamiento en Colombia le corresponde aducir en el proceso arbitral promovido en el extranjero, lo concerniente a la competencia privativa de la jurisdicción colombiana para conocer del asunto, en tanto que a la otra parte interesada en que el adelantamiento del proceso sea en el extranjero le correspondería alegar en el proceso colombiano la excepción correspondiente de cláusula compromisoria o arbitral, a fin de que la decisión, positiva o negativa, que tome el juez colombiano sea la que prevalezca, sin perjuicio, desde luego, de los recursos ordinarios o extraordinarios y medios de defensa que, de acuerdo al orden jurídico colombiano, existan contra ella.

En todo caso dicha prevalencia obedece al carácter de orden público e imperativo de las normas procesales, y al principio general de la territorialidad de estas últimas. De esta manera entonces debe resolverse la situación de competencia que eventualmente pueda plantearse, porque será la decisión en materia de competencia que profiera el juez colombiano la que prevalezca, sin que para ello sea preciso la intervención de un exequátur en dicho punto. 
Revista electrónica de difusión científica - Universidad Sergio Arboleda Bogotá - Colombia

http://www.usergioarboleda.edu.co/civilizar Reservados todos los derechos de autor No. 11

\section{LAUDO ARBITRAL DE LA CÁMARA DE COMERCIO DE BOGOTÁ}

Instituto de Mercadeo Agropecuario, Idema VS Americana de Gestiones Comerciales, Amerco Limitada.

Bogotá, D.C., 13 de junio de 1996

El negocio jurídico se trata de un contrato de compraventa de un alimento no procesado apto para consumo humano bajo la modalidad costo y flete (C\&F), donde Amerco Ltda incumplió con el envío de las mercancías en las fechas establecidas en el contrato además que parte de la mercancía sufrió averías en su calidad por filtraciones en los contenedores en los que fueron transportados.

Amerco Ltda se opuso a las pretensiones excepcionando el cumplimiento del contrato, ausencia de culpa, transmisión de riesgos y división de la cláusula penal. Para esto, solicitó entre otras pruebas que se oficiara a la Cámara de Comercio de Bogotá, a fin de que enviara copia de los Incoterms de 1990, recopilados por la Cámara de Comercio Internacional $(\mathrm{CCl})$ y la recopilación de normas full liners terms a fin y que certifique si es o no costumbre mercantil nacional e internacional.

En primera medida el Tribunal de arbitramento determina que las normas y reglas a aplicar atendiendo al tipo de negocio y cláusulas contenidas en el contrato son las contenidas en el Código de Comercio colombiano y las Incoterms de 1990.

Sin embargo, analizando el contrato observa el Tribunal la existencia de una cláusula en la que se da un tratamiento especial a la determinación de la clase de contrato de que se trata y el régimen de riesgos, cláusula que se aparta ostensiblemente de las normas contenidas tanto en el Código de Comercio como en los Incoterms, al establecer que "por costo y flete, modalidad full liner terms, se entiende el suministro FOB del producto, incluyendo todos los costos de cargue, estiba y arrume de los contenedores y bodegas del buque, el valor de los fletes marítimos hasta el puerto colombiano, los riesgos y pago de demoras en el puerto de cargue, el valor del descargue; hasta dejarlo en el muelle del terminal marítimo, riesgo y pago de demoras en el puerto de descargue".

Así, existe una aparente contradicción en la determinación de la modalidad de contrato de compraventa marítima frente al artículo 1698 del Código de Comercio y la provisión B5 de los Incoterms 1990 en los que se establece que cuando se venda Costo y Flete (C\&F), el vendedor está obligado a pagar el fletamento de la cosa o mercancías pero no del seguro de las mismas ya que la transferencia del dominio se entenderá hecha por la entrega al comprador o a su agente del recibo usual o del conocimiento de embarque limpio.

El Tribunal concluye que ante la prevalencia del principio de la autonomía de la voluntad de las partes en el contrato, normas como el Código de Comercio y los 
Revista electrónica de difusión científica - Universidad Sergio Arboleda Bogotá - Colombia

http://www.usergioarboleda.edu.co/civilizar Reservados todos los derechos de autor No. 11

incoterms -a pesar de su aceptación en el entorno internacional- cumplen un papel supletivo, razón por la cual se dará aplicación a la cláusula estipulada por las partes en forma preferente sobre los usos y costumbres internacionales y las normas del Código de Comercio.

\section{LAUDO ARBITRAL DE LA CÁMARA DE COMERCIO DE BOGOTÁ}

Gran Cadena de Almacenes Colombianos S.A., Cadenalco, S.A. VS Corporación Financiera Nacional y Suramericana S.A., Corfinsura S.A.

Bogotá, D.C., Junio 22 de 1999

La diferencia surgida se basa en un contrato de apertura de crédito documentario Stand By, en el cual el demandante sostiene que el demandado pagó de manera inapropiada o culposa el precio de la carta de crédito.

Por su parte Corfinsura propuso como excepciones la inoponibilidad al confirmante y al emisor de los negocios jurídicos subyacentes, la existencia de una verdadera carta de crédito bajo la modalidad Stand By y el pago apropiado.

Tribunal de arbitramento determina que las normas y reglas a aplicar en el negocio son las normas de derecho interno y las Reglas y Usos Uniformes para Créditos Documentario.

En Colombia es práctica habitual pactar en la misma carta de crédito una cláusula mediante la cual se estipule la aplicación de las reglas y usos uniformes, formando parte integral del texto contractual. En este caso, es claro que estas regulaciones internacionales deben entenderse y aplicarse como verdadero mandato contractual, regido por la obligatoriedad del artículo 1602 del Código Civil, conforme al cual todo contrato legalmente celebrado es una ley para los contratantes, y no puede ser invalidado sino por su consentimiento mutuo o por causas legales.

La carta de crédito Stand By bajo arbitraje consagra que se rige por las RR.UU 500, revisión 1993. Por ello, ante la reclamación de incumplimiento de las obligaciones contractuales al admitir la procedencia del pago de la carta de crédito con la presentación del certificado de beneficiario, el Tribunal examina que según el artículo 13, literal c) de las RR.UU 500, se dispone que si un crédito contiene condiciones respecto de las cuales no se indican los documentos para demostrar su cumplimiento, los bancos considerarán tales condiciones como no establecidas y las ignorarán.

De esta manera la empresa demandada cumplió las obligaciones que le correspondían como emisora de la carta de crédito y reembolsó bien el monto pagado por el banco confirmante. 
Revista electrónica de difusión científica - Universidad Sergio Arboleda Bogotá - Colombia http://www.usergioarboleda.edu.co/civilizar Reservados todos los derechos de autor No. 11 
Revista electrónica de difusión científica - Universidad Sergio Arboleda Bogotá - Colombia

http://www.usergioarboleda.edu.co/civilizar Reservados todos los derechos de autor No. 11

\section{BIBLIOGRAFÍA}

Ascarelli, Tullio. Iniciación al estudio del Derecho Mercantil, Bosch, Barcelona, 1964.

Audit, Bernard, Lex Mercatoria y Arbitraje. Juris Publishing, Londres, 1990.

Bredin, Jean Denis. "A la Recherche de I'æquitas mercatoria" en L'internationalisation du droit: Mélange en I'honneur de Yvon Loussouarn, Dalloz, Paris, pp. 109-118, 1994.

"La loi du juge", en Etudes offertes a Berthold Goldman, Litec Droit,

Paris, 1987. pp. 21 y ss.

Cadena Afanador, Walter René. "La nueva Lex Mercatoria: un caso pionero en la globalización del derecho" en Revista Papel Político, Pontificia Universidad Javeriana, Bogotá Octubre de 2001 (13), pp. 101 - 114

La nueva Lex Mercatoria: la transnacionalización del Derecho, Universidad Libre de Colombia, Bogotá, 2004.

Espinoza Perez, Carlos Antonio. "Crédito documentario: Lex Mercatoria sin fronteras" en La Contratación Mercantil y otros aspectos comerciales, Biblioteca Jurídica Dike, Medellín, 1992, pp. 311 - 325.

"La Lex Mercatoria: el verdadero Derecho de los negociantes internacionales" en Revista de Derecho Privado, Universidad de los Andes, Bogotá, 1.995. pp. 5 - 30.

Feldstein, Sara. Contratos Internacionales: Contratos celebrados por ordenador, Autonomía de la voluntad, Lex Mercatoria, Abeledo-Perrot, Buenos Aires. 1995.

Guardiola Sacarrera, Eduardo. Contratos de colaboración en el comercio internacional, Editorial Bosch, Barcelona, 1998.

Lagarde, Paul. "Approche critique de la Lex Mercatoria" en Etudes offertes a Berthold Goldman, Litec Droit, Paris, 1987, pp. 125 - 149.

El Derecho en la Historia de la Humanidad, PPU, Barcelona, 1.991.

Mantilla Serrano, Fernando. "Ius Mercatorum fuente del derecho internacional" en El Arbitraje en los Conflictos Económicos Internacionales, Cámara de Comercio de Bogotá, Bogotá, 1995, pp. $70-81$.

Sacarrera, Eduardo Guardiola. La Compraventa Internacional, Editorial Bosch, Barcelona, 1994.

Santos, Boaventura de Sousa. "La transnacionalización del campo legal" en Nuevo Orden Global: dimensiones y perspectivas, Universidad Nacional de Colombia, Bogotá, 1996, pp. 229 - 238.

La globalización del derecho: los nuevos caminos de la regulación y la emancipación, Universidad Nacional de Colombia e ILSA, Bogotá, 1.998.

Sombart, Werner. El Capitalismo Moderno, Cavalli, Turín, 1967.

Virally, Michel. "Un tiers droit? Réflexions théoriques" en Etudes offertes a Berthold Goldman, Litec Droit, Paris, 1987, pp. 373 - 385. 